
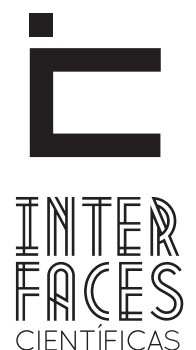

EDUCAÇÃO

ISSN IMPRESSO 2316-333X

ISSN ELETRÔNICO 2316-3828

DOI 10.17564/2316-3828.2016v4n3p91-104

\title{
DIFICULDADES DE APRENDIZAGEM DE CRIANCAS E ADOLESCENTES DA REDE PÚBLICA DE ENSINO: UM FENÔMENO MULTICAUSAL
}

Lindamar Alves Faermann ${ }^{1}$

\section{RESUMO}

Este artigo apresenta reflexões decorrentes de uma pesquisa qualitativa realizada com professores que trabalham em uma escola da rede pública de ensino da cidade de Pindamonhangaba-SP. A pesquisa em tela objetivou conhecer, sob a ótica dos profissionais entrevistados, os motivos que levam crianças e adolescentes a apresentarem dificuldades de aprendizagem. Embora seus depoimentos apontem para questões ligadas, sobretudo, a conflitos familiares e à falta de comprometimento dos pais, estudos revelam que as dificuldades de aprendizagem são multicausais, ou seja, envolvem uma série de fatores vinculados a aspectos biológicos, sociais, culturais, cognitivos e emocionais. O desconhecimento ou omissão dessa problemática por parte dos profissionais tem contribuído para gerar estigmas no contexto escolar, perpetuando práticas discriminatórias e diagnósticos equivocados. Contígua a essa situação, os depoimentos dos profissionais foram reveladores da precariedade no âmbito escolar de recursos materiais, físicos e humanos para lidarem com os alunos que manifestam dificuldades de aprendizagem.

\section{PALAVRAS-CHAVE}

Dificuldades de Aprendizagem. Crianças e Adolescentes. Processos Educativos. 


\section{ABSTRACT}

This article presents reflections arising from qualitative research conducted with teachers who works in the public schools network in the city of Pindamonhangaba-SP. The research aimed to meet, from the perspective of the professionals interviewed, the reasons that lead children and teenagers to demonstrate learning difficulties. Although their statements point to issues related primarily to family disputes and lack of parental involvement, studies show that learning difficulties are multicausal, involve a number of factors linked to biological, social, cultural, cognitive and emotional aspects. The ignorance or omission of this problematic professionals has contributed to gener- ate stigmata in the school context, perpetuating discriminatory practices and misdiagnoses. Adjacent to this situation, the testimony of the professionals were revealing the physical and human material resources precariousness in the school context to deal with students who demonstrate learning difficulties.

\section{KEYWORDS}

Learning Difficulties; Children and Adolescents; Educational Processes

\section{RESUMEN}

Este artículo presenta reflexiones derivadas de investigación cualitativa, realizada con maestros que trabajan en el sistema escolar público del ciudad de Pindamonhangaba-SP. La Investigación está orientada a satisfacer, desde la perspectiva de los profesionales entrevistados, hasta las razones que tienen los niños y adolescentes para presentar dificultades de aprendizaje. Aunque sus declaraciones apuntan a temas relacionados con conflictos familiares y la falta de participación de los padres, los estudios demuestran que los problemas de aprendizaje son multicausales, es decir, implican una serie de factores relacionados con aspectos biológicos, sociales, culturales, cognitivos y emocionales. El descuido u omisión del tema por parte de profesionales ha contribuido a generar estigmas en el contexto escolar, perpetuando las prácticas discriminatorias y diagnósticos equívocos. Junto a esta situación, el testimonio de los profesionales fueron revelando la precariedad en el contexto de materiales escolares, físicos y recursos humanos para hacer frente a los estudiantes que tienen dificultades de aprendizaje.

\section{PALABRAS CLAVE}

Dificultades de aprendizaje. Niños y Adolescentes. Procesos Educativos. 


\section{INTRODUÇ̄̃̃O}

A discussão expressa neste artigo tem como eixo norteador uma pesquisa qualitativa realizada com professores que lecionam em uma escola da rede pública de ensino, localizada na cidade de Pindamonhangaba, interior de São Paulo. A abordagem qualitativa empregada nesta pesquisa buscou os significados atribuídos pelos sujeitos às suas práticas, no espaço em que projetam e "constroem suas vidas e suas relações, ou seja, à compreensão do sentido, dos atos e das decisões dos atores sociais, assim como dos vínculos das ações particulares com o contexto social mais amplo em que se dão" (BAPTISTA, 1999, p. 35).

Dessa feita, buscou-se por meio deste estudo conhecer, sob a ótica dos profissionais entrevistados, os motivos que levam as crianças e os adolescentes da instituição em que trabalham a apresentarem dificuldades de aprendizagem e o papel da escola frente a essa questão. Foram entrevistados três professores. Considerando segundo Martinelli (1999, p. 24) que, nas pesquisas qualitativas trabalha-se com a concepção de sujeito coletivo, isso é, com sujeitos que expressam o conjunto de vivências de seu grupo; o importante nessa abordagem "não é o número de pessoas que vai prestar a informação, mas o significado que esses sujeitos têm em função do que estamos buscando na pesquisa”. Portanto,

[...] o que há de mais significativo nas amostras intencionais ou propositais não se encontra na quantidade final de seus elementos (o "N" dos epidemiologistas), mas na maneira como se concebe a representatividade desses elementos e na qualidade das informações obtidas deles. (FONTANELLA; RICAS; TURATO, 2008, p. 19).

O critério de escolha levou em consideração a disponibilidade dos professores em participarem da pesquisa e a comprovação de no mínimo um ano de trabalho na escola, dada a necessidade de conhecerem seus alunos e sua realidade social.
Como instrumento para coleta de dados utilizou-se a entrevista semiestruturada mediada por um roteiro de perguntas. Essa modalidade de entrevista é utilizada quando se procura saber o que, como e por que algo ocorre. Dessa forma, o pesquisador "tem liberdade para desenvolver cada situação em qualquer direção que considere adequada. É uma forma de poder explorar mais amplamente a questão" (LAKATOS; MARCONI, 2010, p. 279).

A análise do material coletado foi subsidiada por fontes bibliográficas e por um exame criterioso da realidade, em seu movimento e em suas contradições. Para tanto, adotou-se como perspectiva a lógica dialética assumida como método para análise concreta dos fatos reais, isto é:

\section{[...] como maneira de pensar as relações dos homens na sociedade, tendo por ponto de partida a análise crí- tica dos dados factuais. Nesse processo, o sujeito que pesquisa deve ser fiel ao objeto pesquisado, sendo que esta fidelidade não significa retratar o objeto, mas, a partir de sua apreensão, desmontá-lo (analisá-lo) para compreender seu movimento e sua estrutura. (BAP- TISTA, 2009, p. 47)}

Essa perspectiva, caracterizada como método de investigação e de exposição do real, abarca o movimento contraditório da gênese e do desenvolvimento dos fenômenos sociais. Assim, diferentemente do método especulativo, próprio da dialética hegeliana, incapaz de apreender a lógica imanente do real, tem como objeto de análise a realidade concreta, razão pela qual não é nem um método subjetivista - tal como o idealismo que pressupõe um pensamento autonomizado, isto é, um sujeito que, a partir da ideia, atribui sentido e explicação à realidade - nem um método puramente objetivo, como o empirismo acrítico, que toma o pensamento como atividade passiva e a realidade como pronta e acabada: dada imediatamente pela experiência direta. 
$\mathrm{Na}$ análise dos depoimentos dos professores entrevistados, constatou-se que suas narrativas convergiram para a mesma direção, isso é, para esses sujeitos os conflitos familiares e a falta de comprometimento dos pais é o elemento propulsor das dificuldades de aprendizagem das crianças e dos adolescentes. Contudo, pesquisas revelam tratar-se de uma problemática que abarca fatores diversos. Nesse sentido, a indiscriminação do problema, a incompreensão do conceito por parte dos professores e dos familiares e a exígua formação dos profissionais nesta área têm provocado uma série de confusões que se refletem no processo de ensino-aprendizagem dos alunos, na sua vida escolar e social.

Em seus depoimentos os professores também enfatizaram as objeções encontradas para lidarem com alunos que apresentam dificuldades de aprendizagem, em virtude dos parcos e/ou nulos recursos existentes no espaço escolar.

Partindo dessa perspectiva, este artigo tem a intenção de contribuir para o desvendamento e a problematização dessa temática, dirigindo-se aos profissionais envolvidos em processos educativos.

\section{DIFICULDADES DE APRENDIZAGENS: REFLEXÕES TEÓRICAS E CONCEPÇÕES PROFISSIONAIS}

As dificuldades de aprendizagem caracterizam-se por um desempenho escolar aquém do esperado para as condições gerais do aluno, sendo considerada uma problemática de ordem biopsicossocial que envolve fatores endógenos e exógenos aos alunos e que se manifestam, sobretudo, no ambiente escolar (DEL PRETTE \& DEL PRETTE, 2003). Segundo Smith e Strick (2001, p. 33) para alcançarem o desenvolvimento intelectual, "as crianças devem não apenas estarem prontas e serem capazes de aprender, mas também devem ter oportunidades apropriadas de aprendizagem".
A literatura sobre a temática é unânime em afirmar que sua origem e/ou manutenção ocorre por fatores inter-relacionados, portanto, a causa das dificuldades de aprendizagem deve-se a questões como: lacunas no processo de alfabetização, inadequação do aluno ao método pedagógico, mudanças repetitivas de escolas, condições neurológicas diversas (paralisia cerebral, epilepsia), conflitos familiares e pessoais, estimulação inadequada, dentre outros fatores.

As dificuldades de aprendizagem vêm sendo objeto de interesse desde o início do século XIX, sem, de fato, existir um campo consolidado de pesquisas. Ao longo desse período surgiram diferentes formas de abordagens para as dificuldades de aprendizagem. Foi por meio das contribuições de Sanchéz (1998), Smith \& Strick (2001) e Bossa (2002), que se iniciou um processo de sistematização e solidificação dos estudos sobre a temática.

No entanto, embora tenham ocorrido avanços significativos nesse campo, constata-se ainda uma sucessão de imbróglios, visto o conjunto diversificado de fatores que levam os alunos a apresentarem dificuldades de aprendizagem, a própria heterogeneidade das características desses alunos, somados ao desconhecimento teórico dos profissionais que lidam cotidianamente com essa problemática.

Conforme Bossa (2002), a objetividade científica predominante nas ciências naturais tem influenciado as teorias educacionais e, dentro desta lógica, com o intento de manter a ordem do pensamento e das coisas, agrupa-se e ordena-se a vida social, tornando-a mais fácil de analisar, verificar e controlar. 0 aluno tem que aprender no mesmo ritmo e sequência dos demais, comportar-se e manifestar-se dentro dos padrões escolares e, quando foge desta regra, aparecem as mais diversas patologias, transtornos e considerações.

Com base nesse olhar normalizante, deu-se a produção de uma infância "inadaptada". Dentro da concepção de uma infância normal, surgiram as crianças indisciplinadas, as portadoras de dificuldades de 
aprendizagem e as "transgressoras". Não sendo reconhecidas em suas diferenças, são excluídas, deixando de ser consideradas como semelhantes às demais crianças. Assim, com apoio em uma concepção ideal de criança, vão sendo instituídas outras infâncias. (BOSSA, 2002, p. 48).

A produção de uma infância - e acrescente-se de uma adolescência e uma juventude inadaptada - é um fenômeno histórico, mas pelo vulto que tem ocupado na sociedade nos dias atuais, vem chamando atenção de estudiosos das ciências sociais. A questão central que tem preocupado estes profissionais é o uso abusivo de medicamentos prescritos para alunos que apresentam até mesmo "mau comportamento". De acordo com Salomão (2006), muitos alunos são medicados por doenças que, na verdade, têm origem socioemocional e que poderiam ser resolvidas com escolas menos rígidas, mudanças na atitude das famílias e apoio de profissionais especializados.

0 autor observa que, mesmo com o progresso da medicina, há aspectos humanos que não são levados em consideração. "A evolução da medicina relegou a um segundo plano a subjetividade do paciente. As soluções aparecem em forma de comprimidos" (SALOMÃO, 2006, p. 108). Assim, um grande número de "crianças e adolescentes têm sido tratados por transtornos psiquiátricos, quando na verdade, têm um problema psicológico - ou nem isso" (SALOMÃO, 2006, p. 108).

Weiss e Cruz (2000), após estudo específico, destacam que o número de crianças diagnosticadas com dificuldades de aprendizagem encaminhadas para 0 atendimento especializado tem aumentado consideravelmente. Para os autores, o mais agravante nessa situação é o fato de que grande parte desses alunos não apresentou qualquer sintoma que justifique o seu insucesso na escola.

Igualmente Soares (2005), em trabalho intitulado Queixas de aprendizagem: quando a responsabilidade social recai sobre a criança, pesquisou sobre os encaminhamentos recebidos pelo Centro de Valorização da Criança - uma Instituição que oferece serviços na área da saúde mental, ligada à Secretaria de Saúde do Município de Santos-SP, e constatou que muitas queixas relacionadas às dificuldades de aprendizagem não estão ligadas a problemas neurológicos ${ }^{1}$ e psicológicos, nem tampouco, à falta de atenção familiar. Em sua análise, afirma que muitas situações devem-se à ineficiência da política educacional brasileira e às desigualdades decorrentes do modo de produção capitalista, portanto, às expressões e manifestações da questão social.

Os encaminhamentos são realizados pelo Conselho Tutelar, Ministério Público, Organizações Não Governamentais e Unidades de Ensino, por diversas demandas, tais como: violência sexual, pobreza, depressão, apatia e isolamento, negligência, atraso no desenvolvimento cognitivo, evasão escolar e, principalmente, comportamento tido como "desviante" e dificuldades de aprendizagem escolar.

Nesse contexto, Netto (2005) adverte que há uma tendência da sociedade capitalista em psicologizare, acrescentaríamos, em medicalizar a vida social.

\begin{abstract}
É obvio que esta possibilidade tem significância: a individualização dos problemas sociais, sua remissão à problemática singular ("psicológica") dos sujeitos por eles afetados é, como vimos, um elemento constante, embora com gravitação variável, no enfrentamento da "questão social" na idade do monopólio; ela permite - com todas as consequências que daí decorrem - psicologizar os problemas sociais, transferindo a sua atenuação ou proposta de resolução para a modificação e/ou redefinição de características pessoais do indivíduo (é então que emergem, com rebatimentos prático-sociais de monta, as estratégias, retóricas e terapias de ajustamento etc.). (NETTO, 2005, p. 41).
\end{abstract}

Soares (2005) ressalta ainda que parte significativa dos encaminhamentos recebidos no Centro de Valorização da Criança apresenta um componente discriminatório, generalizador e com inadequadas

1. Transtornos de déficit de atenção/hiperatividade (TDHA), dislexia, distúrbios psicológicos, déficit intelectual e outras disfunções cerebrais. 
acepções, e que os diagnósticos são realizados, na maioria das vezes, por profissionais que não possuem qualificações técnicas, fazendo um alerta à ineficiência do sistema escolar brasileiro por não apresentar uma política educacional que contemple, adequadamente, a realidade social dos alunos, principalmente a dos alunos pobres, pelo fato de serem eles o público alvo destas ações.

São encaminhamentos que comprovam a violação dos direitos das crianças, porque não oferecem propostas para alunos cuja experiência é marcada por necessidades sociais e por trajetórias de exclusão. São queixas que revelam o descaso político frente a alunos que precisam de proteção integral, pois quando o aprendizado não ocorre da maneira e no tempo esperado pela escola a responsabilidade social recai sobre 0 aluno e, consequentemente, sobre suas famílias.

Os depoimentos dos profissionais que participaram de nossa pesquisa reforçam essa tendência:

\begin{abstract}
Olha, são variados os motivos, certo. Mas, o problema maior é o comprometimento familiar. Eu tenho um caso de um aluno meu que é um problema gritante. Os pais são separados, ele vive com a avó e aí ninguém cobra nada dele. Então ele é um aluno muito faltoso. A você começa a trabalhar, daqui a pouco ele desinteressa. [...] ele não tem uma aceitação desses problemas e também os pais não aceitam esses problemas, não correm atrás para estar detectando, ajudando a gente com isso, por mais que você fale, por exemplo, esse problema, o aluno faltou no primeiro bimestre, continuou faltando no segundo bimestre, chamamos a mãe, mas sem nenhum interesse. E acaba ficando por isso. (PARTICIPANTE 1).
\end{abstract}

Perspectiva corroborada pelos demais participantes:

Pais que são separados influenciam na aprendizagem do aluno, porque um dá mais atenção e o outro não, um acompanha o rendimento e o outro não. E para criança é muito importante os pais estarem juntos. $\mathrm{Na}$ hora da escola também, das reuniões, das tarefas. São problemas de álcool e outras drogas na família. E isso também, porque a criança vem de uma realidade da casa para a escola, e chega aqui às vezes não quer aprender, porque está preocupada com o que está acontecendo na casa dela. (PARTICIPANTE 2).

Eu acho que são 'n' motivos. [...] Agora, uma grande parte tem comprometimento familiar muito grande. Os pais são separados, então vive ora na casa do pai, ora na casa da mãe, com a avó, não tem uma estrutura, alguém que possa estar acompanhando a criança. E também a aceitação dos pais em relação ao problema, a dificuldade que a criança tem. Então isso torna mais difícil trabalhar, e a gente não tem um apoio. E a família, sendo estruturada, acho que, auxiliaria, acho que pelo menos ajudaria, em resolver um pouco desses problemas apresentados. (PARTICIPANTE 3).

Faz-se necessário lembrar que as análises sobre as dificuldades de aprendizagem devem comportar uma visão de totalidade sobre as causas subjacentes a este fenômeno para que não se aponte a família como seu principal motivo, culpando-a pelo insucesso escolar de seus filhos, alegando que os pais não sabem mais como educá-los e acabam transferindo suas funções e responsabilidades para especialistas e instituições escolares. São análises que desprezam "que o humano põe-se como total e que seu desenvolvimento somente se pode realizar em toda a sua grandeza” (VIEIRA, 2004, p. 11).

Trata-se de análises focalistas e fragmentadas, pois, se formos examinar, há explicações inclusive para entendermos os motivos históricos que instituíram a divisão de tarefas educativas entre a família e a escola. Esta é uma ideia presente na formação da família burguesa. "A medicina social, por meio de uma política higiênica, reduziu a família a este estado de dependência” (BOSSA, 2002, p. 46). Considerava-se, pois, a escola o lugar ideal para promover a educação saudável de crianças e onde as mesmas poderiam ficar imunes aos riscos que suas famílias poderiam ocasionar.

Bossa (2002), ao discutir sobre a organização da família burguesa, ressalta que foi em meados do século XIX que se acentuaram as críticas a respeito das incapacidades das famílias em proteger sua prole, em decorrência das precárias condições de saúde dos 
adultos e do elevado índice de mortalidade infantil. As ideias sanitaristas da época impuseram às famílias um rol de noções acerca da higiene física, disseminando seus preceitos morais e sexuais.

Nesse sentido, é fundamental ter clareza sobre a função social da escola na contemporaneidade, sua responsabilidade no processo de escolarização dos sujeitos. É certo que a família contribui para o êxito desse trabalho, porém, nem todas apresentam condições para tal, em virtude de suas realidades sociais e de suas trajetórias de vida. Segundo Ceccon, Oliveira e Oliveira (1982, p. 13), muitos pais se sentem impotentes porque não conseguem ajudar os filhos como "gostariam nos deveres de casa e na preparação dos exames. Eles chegam exaustos do trabalho, têm que se ocupar dos filhos menores e, muitas vezes, não dominam os conhecimentos e as matérias que a escola exige”.

Ressalta-se que no contexto atual, o Estado tende cada vez mais a se desobrigar da questão social, persistindo na sua gestão a lógica de transferência quase exclusiva para a família de responsabilidades que, em nome da reciprocidade, da solidariedade, da descentralização ou da parceria, a sobrecarregam. Assim, pode-se dizer que a família, longe de ser um "refúgio num mundo sem coração", vem cobrindo as insuficiências do Estado e das políticas públicas, sendo atravessada diretamente pela questão social (CAMPOS, 2004).

É preciso lembrar que, com a crise mundial do capitalismo na década de 1970 e o rompimento do pacto do Estado de Bem-Estar Social nos países Europeus, dilui-se a responsabilidade do Estado na proteção social, acentuando as obrigações familiares no que se refere à manutenção das suas condições de vida, gerando a partir disso um processo de supervalorização das famílias no âmbito das políticas sociais.

A discussão sobre a centralidade das famílias no campo das políticas sociais tem sido debatida com veemência no universo acadêmico, sendo abordada por autores como: Pereira (2006), Mioto (2004), Campos (2004), Esping-Andersen (2000), entre outros.

Tais autores explicitam que, desde a crise mundial do capitalismo nos anos 1970, a família vem sendo redescoberta enquanto recurso privado de bem-estar social e que esse entendimento advém da forma de organização econômico-política dos países, desdobrando-se em suas próprias legislações, servindo como parâmetro para implementarem seus sistemas de proteção social e, consequentemente, sendo ferramentas para subsidiar o trabalho dos profissionais que atuam nesse campo.

Ao trazer essa discussão para o contexto brasileiro, pode-se afirmar que as políticas sociais são implementadas mediante a partilha de responsabilidades entre as famílias e o Estado. A ideologia que perpassa essas políticas está abrigada na vasta legislação nacional: Constituição Federal de 1988, Lei de Diretrizes e Bases da Educação Nacional de 1996, Lei das Pessoas com Deficiência de 1989, Estatuto da Criança e do Adolescente de 1990, Lei do Idoso de 1994, Política Nacional da Assistência Social de 2004, entre outros dispositivos legais.

Não é preciso tanto esforço analítico para constatar nessas leis a obrigatoriedade dos filhos cuidarem de seus pais em situações de velhice, pobreza e doença, assim como a obrigatoriedade dos pais pelo sustento, guarda e educação dos filhos. Ainda é previsto na referida legislação a obrigatoriedade dos membros familiares no cuidado dos idosos, inclusive com orientação de, em casos de abandono e omissão, responderem processo judicial, estando sujeitos à pena de detenção.

Observa-se ainda, na legislação supracitada, outras análogas que neste momento não cabe aprofundar. 0 fato é que há nesses dispositivos legais um apelo à responsabilidade familiar, um reforço à sua posição e seus deveres na vida em sociedade. Além disso, há uma tendência das políticas privilegiarem "a dependência das condições do grupo familiar, para o 
reconhecimento de direitos individuais aos meios de subsistência" (CAMPOS, 2004, p. 15), o que, a nosso ver, é problemático, uma vez que o reconhecimento do direito está sujeito a certas condicionalidades.

Nessa direção, Zimmermann (2006) assinala que sob o viés dos direitos sociais não se pode atribuir a responsabilidade da proteção aos indivíduos e nem às famílias, e sim, responsabilizar o Estado por não garantir direitos que tendem a ser tratados com certas cláusulas e restrições.

\section{PAPEL DA ESCOLA FRENTE ÀS DIFICULDADES DE APRENDIZAGEM DE SEUS ALUNOS}

A educação é um direito social universal, cabendo à escola possibilitar o acesso dos alunos à escrita e à leitura e educar para a liberdade, para a interiorização de valores e da cultura, portanto, colaborar para a autonomia, para a cidadania e para a emancipação dos sujeitos. Nesse sentido, a escola deve oferecer conteúdos, recursos e serviços que estimulem e garantam esses objetivos.

Tais pressupostos referem-se também ao atendimento das peculiaridades dos alunos que apresentam dificuldades de aprendizagem e àqueles incluídos na educação especial. Assim, a política educacional brasileira, expressa nos dispositivos legais, evidencia o direito à educação e a valorização da diversidade nesse âmbito. Para tanto, prevê a existência de um sistema educacional inclusivo, de instituições escolares ou classes com serviços e profissionais especializados e com recursos multifuncionais que atendam as demandas dos estudantes.

Todavia, essa não tem sido a realidade vivenciada por muitos profissionais da educação no país. Pesquisas na área mostram que dentre as dificuldades encontradas, destacam-se a precarização do trabatho docente, a falta de infraestrutura em geral para o desenvolvimento das atividades e para o encami- nhamento das demandas dos alunos que emergem no contexto escolar e a desmotivação por parte do alunado (TOKUYOCHI, 2008).

Assim, na contramão do que expressa a política educacional no Brasil, os professores que participaram dessa pesquisa sinalizaram objeções para lidarem com as dificuldades de aprendizagem das crianças e dos adolescentes na escola onde trabalham.

A gente não tem na escola uma estrutura para trabalhar com as crianças que tem dificuldades de aprendizagem, então a gente praticamente faz um laboratório com elas, dentro do que a gente estudou, do que a gente conhece sobre a aprendizagem, a evolução da criança, a gente vai tentando trabalhar. Só que a partir do momento que a gente vê que os recursos não são suficientes, aí partimos para um especialista. Só que, infelizmente esse trabalho é muito moroso, e muitas vezes a criança passa o ano inteirinho com a gente e não consegue ser atendida. [...] Então trabalhamos, dentro das condições que temos na escola. Se tivesse esse acompanhamento, facilitaria nossa vida. (PARTICIPANTE 3).

A despeito da diversidade da população escolar, a educação é um direito universal, devendo ser resguardada independentemente de gênero, etnia, idade, classe social ou das necessidades educacionais dos alunos. Daí o acesso à escola extrapolar o ato da matrícula e implicar na apropriação do conhecimento, do saber e das oportunidades educativas à totalidade dos alunos. Nessa perspectiva, a legislação brasileira sobre a educação inclusiva indica a obrigatoriedade de sistemas de apoio para o atendimento de alunos com dificuldades de aprendizagem. Com base em suas prescrições, os sistemas de apoio devem começar dentro da própria escola com vistas à acessibilidade dos alunos, constituindo-se em estratégias para eliminar as barreiras existentes e para favorecer o desenvolvimento da aprendizagem. Nesse contexto, a família, a rede de serviços e as políticas intersetoriais tornam-se parte essencial dos sistemas de apoio.

Mas ora, segundo a professora entrevistada, a previsão normativa não se sustenta na realidade. Entre a 
promessa legal e a vida cotidiana há um descompasso. Porquanto, há que se ter claro que a sua efetivação não se dá pela simples vigência da legislação - a afirmação jurídica é necessária, mas é preciso políticas concretas para tal. O Estado brasileiro deve incorporar os princípios enunciados na educação inclusiva, consolidando o acesso à educação para todos, garantindo condições para que alunos com dificuldades de aprendizagem possam aprender e se manter na escola. É exatamente neste sentido, lembra Freire (1996, p. 26), “que ensinar não se esgota no 'tratamento' do objeto ou do conteúdo, superficialmente feito, mas se alonga à produção das condições em que aprender criticamente é possível”.

Embora a educação inclusiva se expresse em uma diretriz constitucional (art. 208, III) e disponha de um contingente significativo de decretos, leis, portarias para garanti-la - sendo parte integrante da política governamental há, pelo menos, duas décadas, no escopo em que hoje se encontra definida -, ainda não se produziram as mudanças necessárias na realidade escolar.

Portanto, a perspectiva de educação para todos constitui um grande desafio, quando a realidade aponta para uma parcela numerosa de alunos excluídos ou não atendidos no sistema educacional. A educação é condição para a existência de sociedades justas e, enquanto existir a exclusão nesse campo, não há consolidação da democracia. Enfrentar esse desafio é condição essencial para concretizar a democracia e as aspirações de desenvolvimento da educação brasileira. Quando uma criança não frequenta a escola, é nítida a carência de uma dimensão na formação de sua vida. Nesse sentido, a educação nos termos de Sacristán (2001), entendida como um projeto humanizador, foi e continua sendo uma aposta pelo progresso da sociedade e dos seres humanos.

Ao se refletir sobre o sentido da educação inclusiva, deve-se considerar a diversidade dos alunos e seu direito à igualdade no processo de escolarização.
Em vista disso, o termo inclusão tem como horizonte o compromisso com todos, exigindo das instituições escolares estruturas adequadas, serviços e tecnologias de apoio, mudanças curriculares e formação qualificada dos profissionais. Essas condições exigem a atenção do Estado para viabilizar por meio de políticas o acesso à aprendizagem, ao conhecimento e ao conjunto de experiências curriculares, disponibilizadas no ambiente educacional a todos os alunos, indiscriminadamente - o que demanda a reestruturação das escolas para responderem às necessidades educacionais do tempo presente.

O sistema escolar organizou-se historicamente para atender o aluno ideal, o que aprende e que corresponde às expectativas da escola, suas regras, normas e os conhecimentos instituídos e, quando isso não ocorre, ou as escolas convivem com a diversidade ou submetem-na a um padrão que a anule, compelindo os alunos a se adequarem aos preceitos escolares; aqueles que destoarem da "padronização normativa, aqueles que não seguirem o ritmo e a seqüência cairão na "anormalidade", seja em sua área negativa - os "atrasados", os "manter”, os fracassados, os reprovados (SACRISTÁN, 2001, p. 87) - ou ainda, conforme ressalta o autor, "seja em sua área positiva - os "adiantados", os "superdotados”, os notáveis e destacados - (SACRISTÁN, 2001, p. 87).

Destarte, as instituições escolares, ao reproduzirem estas práticas de classificação, padronização e disciplina, continuam operando com identidades atribuídas e, por conseguinte, fomentando "práticas reiterativas, reificadas, sem afinidade com o momento histórico e social” (MARTINELLI, 2005, p. 8).

Afora essa questão, o aluno que apresenta dificuldades de aprendizagem não pode ser visto como responsabilidade exclusiva do professor. A atitude solitária do profissional frente a essa realidade, somada às pressões institucionais, pode levar à naturalização ou à mera aceitação de um contexto de trabalho perverso que se contrapõe às finalidades educativas. Por isso, a negação 
dessa situação é fundamental e impõe-se a ela a luta coletiva para construir a escola que queremos.

Nessa direção, outros depoimentos foram reveladores das objeções que o professores encontram para lidarem com as dificuldades de aprendizagem das crianças e dos adolescentes na escola onde trabalham.

Quando o aluno chega para nós, fazemos uma avaliação, um pequeno diagnóstico dentro do nosso conhecimento. Quando se trata de problema fonoaudiológico ou psicológico, conversamos com os pais, mas muitos não aceitam, deixam eles aqui e vai passando pelo tempo. Depois de conversado com os pais, encaminhamos para os profissionais adequados. Aí, cai naquele outro sistema que eles demoram também para atender, então demora um ano e meio a dois anos. Muitos são problemas de fono, que a criança fala errado e escreve errado, que detectamos logo no início e que poderia ser sanado, mas eles não são atendidos. (PARTICIPANTE 1).

Observa-se, conforme o seu depoimento, que as manifestações de dificuldades de aprendizagem apresentam-se na escola como um contínuo, desde situações leves e transitórias que poderiam ser resolvidas rapidamente, com envolvimento dos familiares e mediante a funcionalidade da rede de serviços, até situações mais graves e persistentes que requerem o uso de recursos especiais para a sua solução. Atender a esse contínuo de dificuldades requer respostas políticas e educacionais, não apenas boa vontade de seus agentes.

O movimento nacional para incluir todos os alunos na escola tem tencionado debates e práticas direcionadas à construção de uma "escola para todos", com políticas públicas eficazes e com uma pedagogia transformadora. Esse processo vem desde a década de 1990, aportando novas perspectivas educacionais para os alunos com dificuldades de aprendizagem, exigindo mudanças no sistema educacional atualmente disponível. Essas mudanças implicam, necessariamente, no atendimento dos alunos, sem distinção de condições linguísticas, sensoriais, cognitivas, físicas, emocionais, culturais e socioeconômicas, e requerem instituições planejadas que dêem conta da diversidade dos alunos e ofereçam respostas adequadas às suas demandas, suas particularidades e suas necessidades.

No plano teórico-ideológico, a educação inclusiva expressa indubitavelmente uma proposta politicamente correta, na medida em que materializa valores e princípios norteados pela igualdade de direitos. Todavia, no plano prático-concreto, requer a superação dos obstáculos existentes no sistema regular de ensino. Seu ideário esbarra-se inexoravelmente com dificuldades operacionais e pragmáticas, como a ineficácia das políticas, a inoperância da rede de atendimento, os parcos ou nulos recursos físicos, materiais, pedagógicos e humanos para o trabalho com alunos com dificuldades de aprendizagem.

Quando se preconiza a necessidade de um rol de recursos e de serviços para atender o aluno com necessidades educacionais diversas, evidencia-se uma clara opção pela política de inclusão no texto da lei, não devendo a inclusão, seja como política ou como princípio norteador, ser penalizada em decorrência dos erros que têm sido identificados na sua operacionalização, nas últimas décadas.

O acesso à educação pública, laica, gratuita e de qualidade é um dos caminhos para a construção da igualdade, mas a sua falta ou as diferenças na forma de escolarização conduzem à desigualdade social. Lamentavelmente, em pleno século XXI, em meio a tantos avanços tecnológicos e científicos, convivemos com escolas que impedem, cerceiam ou não dispõem de recursos para atender os alunos com dificuldades de aprendizagem.

Diante desse contexto, Sacristán (2001) adverte que a escola ainda não cumpriu seu programa de educação universal. 0 caminho percorrido foi muito breve e mal transitado. Enquanto um direito social universal, proposto no século $X X$, ou a escola integra a todos ou ela trai esse direito. 0 autor destaca que 0 potencial mais significativo que a educação desempenha hoje é o da inclusão e a sua não realização favo- 
rece o abismo entre os sujeitos e se coloca como um problema no campo da justiça. É injusto não oferecer educação de qualidade para todos.

Entende-se que o paradigma da inclusão implica na transformação dos sistemas de ensino, no cumprimento das leis, na viabilização de políticas públicas e na responsabilização do Estado nesse processo, de modo a assegurar aos alunos condições de acesso e, principalmente, de permanência, com sucesso, nas escolas. Ademais, exige mudanças curriculares, visto que a segregação pode ser enfrentada com uma pedagogia crítica que trate das diferenças, aproveitando a flexibilidade que o desenvolvimento do currículo permite.

A descrença de que todos os alunos podem crescer, no sentido de ampliar suas habilidades e capacidades, faz com que o principio de universalidade da educação perca o seu fundamento mais digno. É condição antropológica do ser humano como ser cultural estar aberto às mais diversas possibilidades.

O depoimento, abaixo, também reforça os constrangimentos vivenciados pelos professores para lidarem com as dificuldades de aprendizagem que os alunos apresentam no cotidiano escolar.

Após o diagnóstico, é feito um trabalho diário, do professor com o aluno. Encaminhamos também o aluno para a recuperação paralela. E o professor dá uma recuperação contínua para ele dentro da sala de aula, e logicamente que ele vai fazer uma atividade diferenciada dos demais alunos. Esse trabalho diferenciado fica às vezes muito difícil de fazer dependendo da sala - porque uma sala numerosa, e você tem que fazer um trabalho diferenciado. Às vezes o próprio aluno fica com vergonha de participar daquele trabalho. Os outros alunos não colaboram. É difícil você fazer os outros alunos entenderem que o colega precisa de uma atenção em especial. Então, com o número excessivo de alunos na sala de aula, é muito mais difícil conseguir o êxito. (PARTICIPANTE 2).

Sobre esse aspecto, Bossa afirma que "a vida da criança, em nossa cultura, gira predominantemente em torno da escola e não aprender o que é determinado por ela traz sofrimento, rejeição e outras graves consequências" (BOSSA, 2002, p. 35).

Os depoimentos dos professores são reveladores dos desafios que conformam o ensino público brasileiro, os quais se devem à insuficiência do Estado para o enfrentamento dessa questão. Certamente, que a realidade de trabalho dos professores e as condições infraestruturais das escolas influenciam nos resultados e na qualidade do trabalho que realizam, corroborando para o mal-estar docente.

Embora no plano legal esteja assegurada a qualidade da educação, a superação das desigualdades e o estímulo à diversidade no interior da escola, na prática não são oferecidas condições reais para efetivá-las. Uma escola pública de qualidade requer, além de profissionais qualificados e valorizados, recursos suficientes para o trabalho educativo. Dessa forma, os resultados mostram a necessidade de tornar essa instituição um espaço inclusivo de fato.

Kramer (2006) lembra que uma educação que busca contribuir para a construção de uma sociedade democrática, uma educação pública que tem seu compromisso firmado com a justiça social e, portanto, com a transformação precisa ser popular e, neste sentido, precisa abraçar carinhosamente e respeitosamente a questão da cidadania. Para tanto, há que se considerar a dimensão histórica, política, social e econômica em que a educação se insere, bem como a dimensão cotidiana que conforma o seu acontecer na prática.

\section{CONSIDERAÇÕES FINAIS}

A aprendizagem é resultado de uma complexa atividade mental que envolve processos de percepções, emoções, memórias, conhecimentos prévios, vivências concretas, entre outras mediações (BOSSA, 2002); mesmo se tratando de uma atividade inerente ao homem, diversos fatores influenciam para que ela 
ocorra ou não satisfatoriamente. Logo, não se constituindo num processo linear e previsível, surgem as dificuldades de aprendizagem, caracterizadas segundo os autores estudados como,

[...] uma ampla gama de problemas que podem afetar qualquer área do desempenho acadêmico. Raramente, elas podem ser atribuídas a uma única causa: muitos aspectos diferentes podem prejudicar o funcionamento cerebral, e os problemas psicológicos dessas crianças frequentemente são complicados, até certo ponto, por seus ambientes domésticos e escolar. As dificuldades de aprendizagem podem ser divididas em tipos gerais, mas uma vez que, com frequência, ocorrem em combinações - e também variam imensamente em gravidade -, pode ser muito difícil perceber o que os estudantes agrupados sob esse rótulo têm em comum. (SMITH; STRICK, 2001, p. 15).

A não apropriação por parte dos profissionais da educação de ferramentas para lidar com as dificuldades de aprendizagem, suas causas e suas consequências interfere sobremaneira na vida escolar e social discente, ocasionado a má qualidade na prestação de serviços aos alunos e aos seus familiares e a reprodução do preconceito e da estigmatização no âmbito escolar. Esta estigmatização vem reforçar a transferência para o campo da patologia individual ou da questão moral e familiar um fenômeno que é multicausal.

Há que se ter claro que o processo de aprendizagem não ocorre de maneira uniforme; os sujeitos aprendem e agem de acordo com o seu meio cultural e social, a partir dos estímulos que recebem e das experiências que vivenciam. A diversidade faz parte da vida humana, não há como padronizá-la; cada sujeito revela sua idiossincrasia, mesmo estando inserido na coletividade. Se vivemos e nos situamos em espaços que se expressam como democráticos, é esperado que se estabeleçam relações de tolerância, negociação e respeito.

Considera-se importante reavaliar funções e práticas assumidas historicamente pela escola, para que ela se torne efetivamente um lugar de encontro hu- mano, de garantia de direitos e de alegria, consubstanciado com o seu papel central que é o de difusão e incremento do conhecimento e da cultura em geral.

Freire (1996) destaca que o sentido primeiro da pedagogia é o de reconhecer que a formação do ser humano se torna possível ao longo do tempo. Daí Arroyo (2004) sublinhar a premência de a escola equacionar as propostas pedagógicas às condições de vida dos alunos, aos seus contextos socioeconômicos e culturais, aos seus tempos, ciclos e trajetórias de vida. Para esse autor, esta é uma tarefa inadiável neste novo milênio e que demanda a presença de todos os profissionais envolvidos na educação.

Depreende-se, diante das reflexões construídas neste artigo, que se por um lado existem entraves políticos e materiais para que os professores respondam às dificuldades de aprendizagem dos seus alunos, por outro, os professores necessitam compreender essa questão sob um viés crítico, ou seja, a partir de uma análise de totalidade. Nesse sentido, a "dificuldade de aprendizagem é um desafio, que propõe à escola rever suas estratégias e ao professor rever suas concepções" (ZYLBERBERG, 2007, p. 246).

\section{REFERÊNCIAS}

ARROYO, M. G. Imagens quebradas: trajetórias e tempos de alunos e mestres. Petrópolis: Vozes, 2004.

BAPTISTA, M. V. A relação teoria/método: base do diálogo profissional com a realidade. In: BAPTISTA, M. V.; BATTINI, O. A prática profissional do

assistente social: teoria, ação, construção do conhecimento. São Paulo: Veras, 2009.

BAPTISTA. M. V. (Org.). 0 método da economia

política de Karl Marx. São Paulo: PUC-SP, 1999

(mimeo). 21p. (Texto comentado por vários autores). 
BOSSA, N. A. Fracasso escolar: um olhar psicopedagógico. Porto Alegre: Artmed, 2002.

CAMPOS, M. S. Família e política social: caso brasileiro e estudo particular em São Paulo. VIII Congresso Luso-Afro Brasileiro de Ciências Sociais, Anais..., Coimbra- Portugal, 2004.

CECCON, C.; OLIVEIRA, M. D. de; OLIVEIRA, $R$. D. de. A vida na escola e a escola na vida. Petrópolis: Vozes, 1982.

DEL PRETTE, Z. A. P; DEL PRETTE, A. Habilidades sociais, desenvolvimento e aprendizagem: questões conceituais, avaliação e intervenção. Campinas: Alinea, 2003.

FONTANELLA, B. J. B.; RICAS, J.; TURATO, E. R. Amostragem por saturação em pesquisas qualitativas em saúde: contribuições teóricas. Caderno de Saúde Pública, n.24. Rio de Janeiro, jan. 2008. p.17-27. Disponível em: <http://www.scielo.br/pdf/csp/ v24n1/02.pdf>. Acesso em: 5 jan. 2015.

FREIRE, P. Pedagogia da autonomia: saberes necessários à prática educativa. São Paulo: Paz e Terra, 1996.

KRAMER, S. Por entre as pedras: arma e sonho na escola. 3.ed. São Paulo: Ática, 2006.

LAKÁTOS, E. M.; MARCONI, M. de A. Metodologia científica. 5.ed. São Paulo: Atlas, 2010.

MARTINELLI, M. L. Pesquisa qualitativa: um instigante desafio. São Paulo: Veras, 1999.

MARTINELLI, M. L. Pensar a identidade: eis a tarefa. Um ensaio sobre a identidade profissional do Serviço Social. In: KARSCH, U. (Org.). Estudos do serviço social: Brasil e Portugal. São Paulo: Pontifícia Universidade Católica de São Paulo; EDUC, 2005. p.65-79.
NETTO, José Paulo. Capitalismo monopolista e serviço social. 4.ed. São Paulo: Cortez, 2005.

SACRISTÁN, J. G. A educação obrigatória: seu sentido educativo e social. São Paulo: Artmed, 2001.

SALOMÃO, A. O preço da ignorância. Exame, n.877, São Paulo, 27 set. 2006. p.20-26.

SMITH, C.; STRICK, L. Dificuldades de aprendizagem de A a Z: um guia completo para pais e educadores. Porto Alegre: Artmed, 2001.

SOARES, R. M. R. A. L. Queixas de aprendizagem: quando a responsabilidade social recai sobre a criança. 2005. 154f. Dissertação (Mestrado em Serviço Social) - Pontifícia Universidade Católica de São Paulo, São Paulo, 2005.

TOKUYOCHI, J. H. et al. Retrato dos professores de educação física das escolas estaduais do estado de São Paulo. Revista Motriz, v.14, n.4, Rio Claro, out./ dez. 2008. p.418-428.

VIEIRA, E. Os direitos e a política social. São Paulo: Cortez, 2004.

WEISS, A. M. L; CRUZ, M. L. R. A informática e os problemas escolares de aprendizagem. Rio de Janeiro: DP\&A, 2000.

ZIMMERMANN, C. R. Os programas sociais sob a ótica dos direitos humanos: o caso do Bolsa Família do governo Lula no Brasil. Sur. Revista Internacional de Direitos Humanos, ano III, n.4, 2006.

ZYLBERBERG, T. P. Possibilidades corporais como expressão da inteligência humana no processo ensino-aprendizagem. 2007. 280f. Tese (Doutorado em Educação Física) - Faculdade de Educação Física, Universidade Estadual de Campinas, UNICAMP, Campinas, 2007. 
